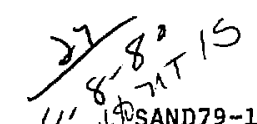

4 '4SAND79-1666

2 Unlimited Release

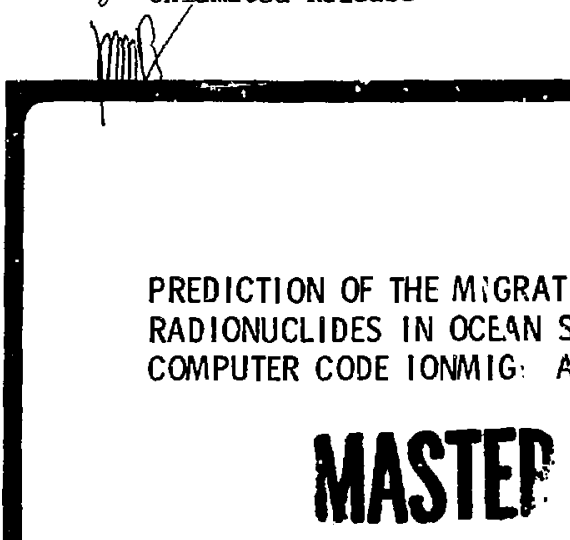

A. J. RUSSO

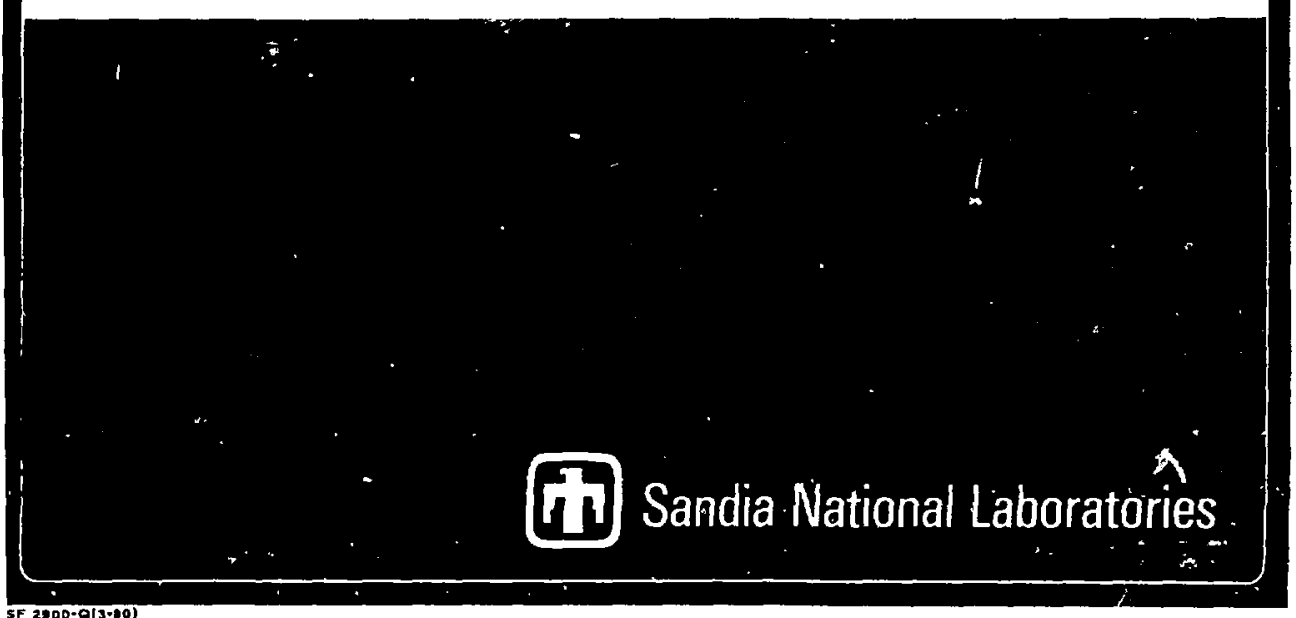


SAND79-1666

Unlimited Release

\section{PREDICTION OF THE MIGRATION OF SEVERAL RADIONUCLIDES IN OCEAN SEDIMENT WITH THE COMPUTER CODE IONMIG: \\ A PRELIMINARY REPORT*}

A. J. Russo

Fluid Mechenics and theat Transfer Division 5512

Sandia National Laboratories *

Albuquerque, NM

87185

May 1980

ABSTRACT

A computer code, IONMIG, which is lised to calculate the far-field transport of radionuclides through ocean sediment by diffusion and convection is described. The code uses a two-dimensional, axisymmetric, explicit finite difference formulation. Preliminary results for several species (Cs, PU, I, TC) are given.

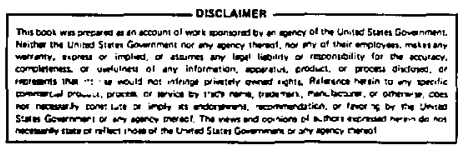
This work was supported by the U.S. Department of Energy under contract
DE-AC0 4-76DPOD789.

** U.S. Department of Energy facility. 
CONTENTS

$\begin{array}{lc} & \text { Page } \\ \text { INTRODUCTION } & 5 \\ \text { CODE DESCRIPTION } & 6 \\ \text { Theory } & 6 \\ \text { Geometry and goundary Conditions } & 9 \\ \quad \text { Input Param:atars } & 12 \\ \text { RESULTS } & 17 \\ \text { CONCLUSIONS } & 22 \\ \text { REFERENCES } & 23\end{array}$




\section{ACKNOWLEDGEMENTS}

The author would like to thank David K. Gartling, who developed the fluidthermodynamic code, MARIAH, and provided calculations of velocities and temperatures used in obtaining these preliminary resulta. 


\section{INTRODUCTION}

As part of a study to determine the feasibility of radioactive waste lisposal in seabed sediment, a radionuclide mugration code, IONMIG, is being developed. This code is a two-dimensional planar or axisymmetric code which solves the transpor: equation including convection, axial and transverse dispersion, molecular diffusion, concentration dependent adsorptiv $n$ and radioactive derij. Assumptions used in its formulation are that the presence of the radionuclides does not change the fluid properties or the behavior of other nuclides and that absorbtive processes are reversible and describable in terms of an empirically determined equilibrium constant. Near-field details are not treated and species are injected as volumetric source terms. A brief description of the code is given in the CODE DESCRIPTION section of this report.

IONMIG diffexs from another sandia nuclide migration code, SwIFT, $^{2}$ which was developed with Intera Corporation to analyze transport through hydrologic formations, in that it is much simpler to use (SWIFT input requirements are about 30 times greater than IONMIG's). IONMIG can use concentration dependent adsorption coefficients and is part of a modular solution system (IONMIG interEaces with the incompressible fluid thermo code, MarIAH, and the plot code, SEAPLT).

The purpose of this report is to describe some preliminary results on several species which are representative of the elements of concern in a waste canister inventory. These are ${ }^{137} \mathrm{Cs},{ }^{99} \mathrm{Tc},{ }^{129} \mathrm{I}$, and ${ }^{239} \mathrm{Pu}$. 
CODE DESCPIPTION

Theory

The equations describing the migration of contaminant ions in a porous saturated bed are of the form:

$$
\frac{\partial\left(C_{i} \in K_{i}\right)}{\partial t}+\nabla \cdot\left(C_{i} \vec{v}\right)=-\sum_{k=1}^{N}\left(\lambda_{i k} K_{i} \varepsilon C_{i}\right)+\sum_{k=1}^{N} \lambda_{k i} K_{k} \varepsilon C_{k}+s_{i},
$$

where,

$$
\begin{aligned}
& c_{i}=\text { the ion species concentration } 0 \mathrm{~kg} / \mathrm{m}^{3} \text { ) } \\
& \varepsilon=\text { the porosity of the medium } \\
& k_{i}=\text { the species equij.ibrium coefficient for species } i= \\
& \left(1+\frac{1-\varepsilon}{\varepsilon} \rho_{\text {soil }} k_{d_{i}}\right) \text { where } k_{d} \text { is the equilibrium distribution } \\
& \text { coefficient } \\
& \lambda_{i k}=\text { the radioactive decay rate from species } i \text { to species } k \\
& s_{i}=\text { a source term for continuous or step function addition of ions } \\
& \text { corresponding to the leach rate } \\
& \vec{v}=\text { the total ion velocity which is assumed to be of the form: } \\
& u-\frac{D_{x}}{C_{i}} \frac{\partial C_{i}}{\partial x} \vec{i}+v-\frac{D_{y}}{C_{i}} \frac{\partial C_{i}}{\partial y} \vec{j} \\
& u=\text { convective velocity in the } x \text {-direction } \\
& \mathrm{v}=\text { convective velocity in the } \mathrm{y} \text {-direction } \\
& D_{x, y}=\text { diffusion dispersion coefficient in the } x, y \text {-direction } \\
& D_{x}=a_{L}|u|+a_{T}|v|+D_{0} \\
& \alpha_{L}, \alpha_{T}=\text { longitudinal and transverse dispersion coefficients } \\
& \mathrm{D}_{\mathrm{O}}=\text { molecular diffusion coefficient }
\end{aligned}
$$


to a level in which they will disappear in several global time steps. This permits the inclusion of transition species in the chain without going to excessively smail time steps, but of course, the instantaneous concentrations of such short lived species will be greatly overestimated and should not be considered as part of the useable output of the code. Any element for which $\lambda \Delta t>3$ is treated as such a transition species.

In order to retain the flexibility of use provided by the options of axisymmetric geometry an variable mesh calculations, conservation differencing, which becomes rather unwieldy for those options, was not used. It is possible, therefore, that discretization and truncation errors may introduce some source error into the calculations. To partially correct for that possibility, a separate and more accurate time integration of the global quantities is performed and compared with the mesh point summations. An option to correct the mesh point values at each time step is included in the code.

\section{Geometry and Boundary Conditions}

The computational domain is a rectangliar region, with boundary conditions as indicated in figure 1 , which represents a cross section of as axisymmetric region with $x$ as the radial coordinate. The concentrations and sources are initially specified and the code computes subsequent distributions. If an external convective velocity field is not provided, an internally generated conservative convective cell field is assumed with its peak velocity specified as input data (peak may be zero).

The rectangular region shown in Figure 2 represents a cross section of the axisymetric computational domain, as in Figure 1 , with the dimensions used in the calculations and the canister location indicated. The gtreamlines shown in Figure 2 are hose calculated with the finite element code, MARIAH, at 1.00 years after burial. The canister is assumed to be $3 \mathrm{~m}$ long and $0.3 \mathrm{~m}$ in diameter and to contain 10 year old reactor waste. It is buried with its center 30 metres below the ocean-sediment interface. 


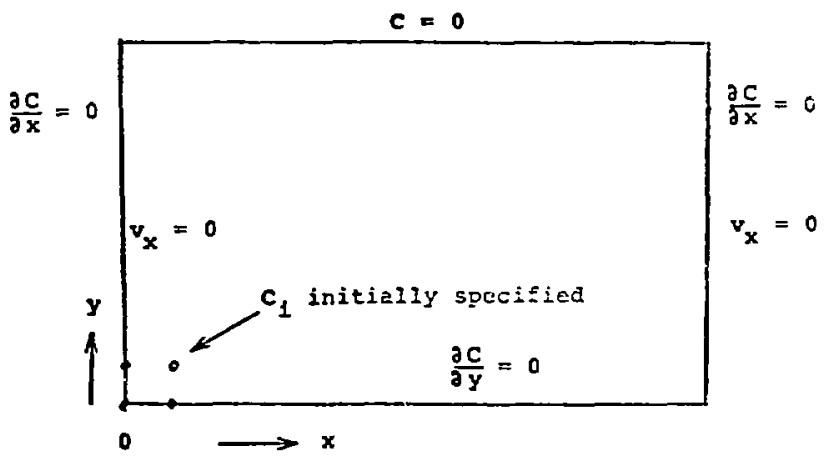

FIGURE 1. Geometry and Boundary Conditions Assumed in IONMIG. 


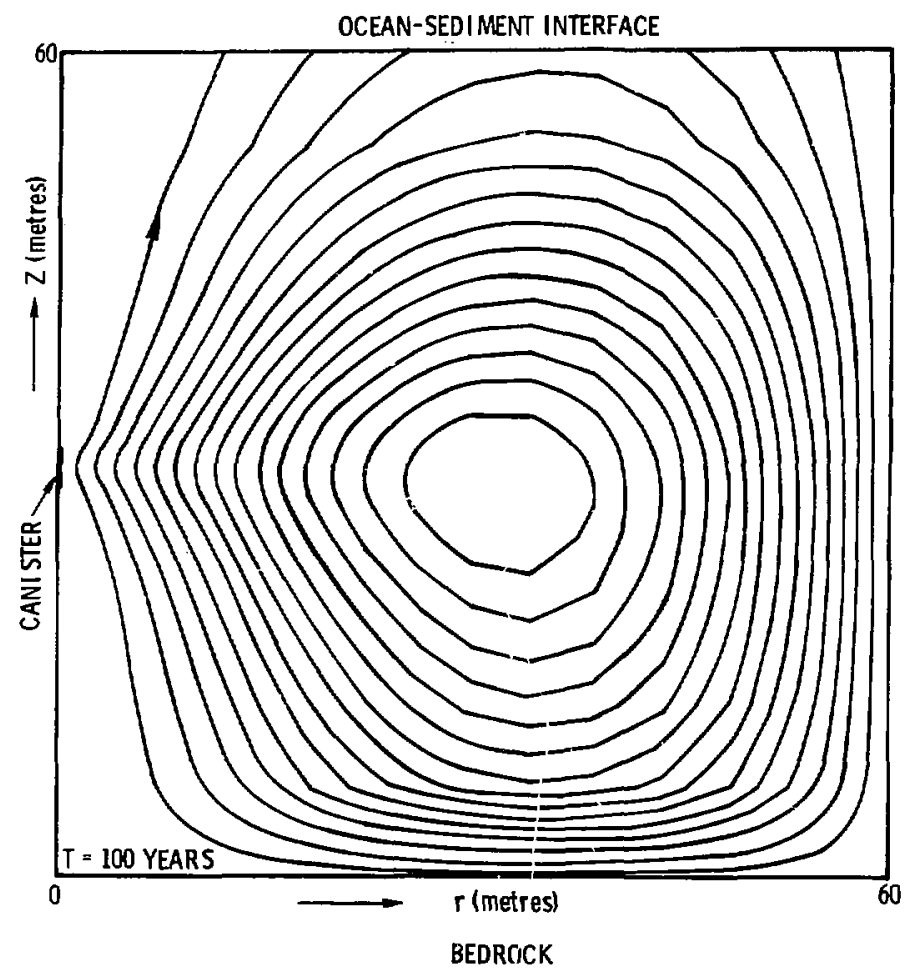

FIGURE 2. GEOMETRY AND STREAMLINES IN THE SEDIMENT COMPUTATIONAL REGION. 
Input Parameters

The heat generated by the canister is assumed to be $1.5 \mathrm{~kW}$ at burial and to be decaying according to a schedule given in the ORIGEN code. ${ }^{3}$ The temperature history near the canister surface is shown in Figure 3 . In a few hundred

years, the temperature is within a few degrees of the ambient $\left(1.5^{\circ} \mathrm{C}\right)$. The same is true for all points in the region.

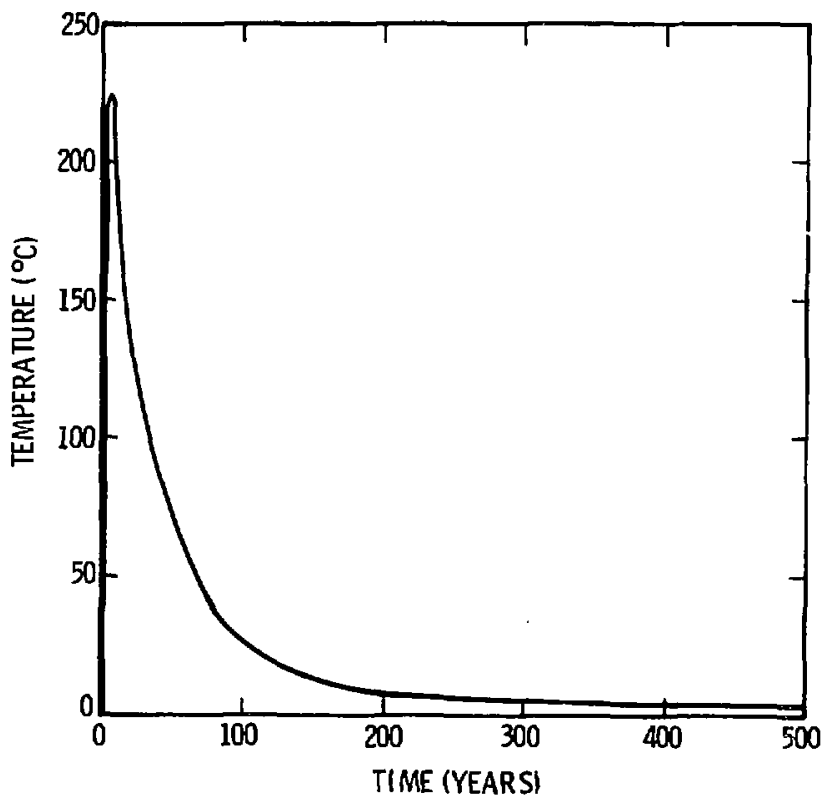

FI GURE 3. TEMPERATURE HI STORY ADJACENT TO A WASTE CANI STER 30 METRES BELOW THE SEDIMENT SURFACE. 
The velocity variation with time at its maximum point adjacent to the canister is shown in Figure 4. It is seen that this velocity is very small, and afte 100 years, convective transport is negligible compared to molecular diffusion.

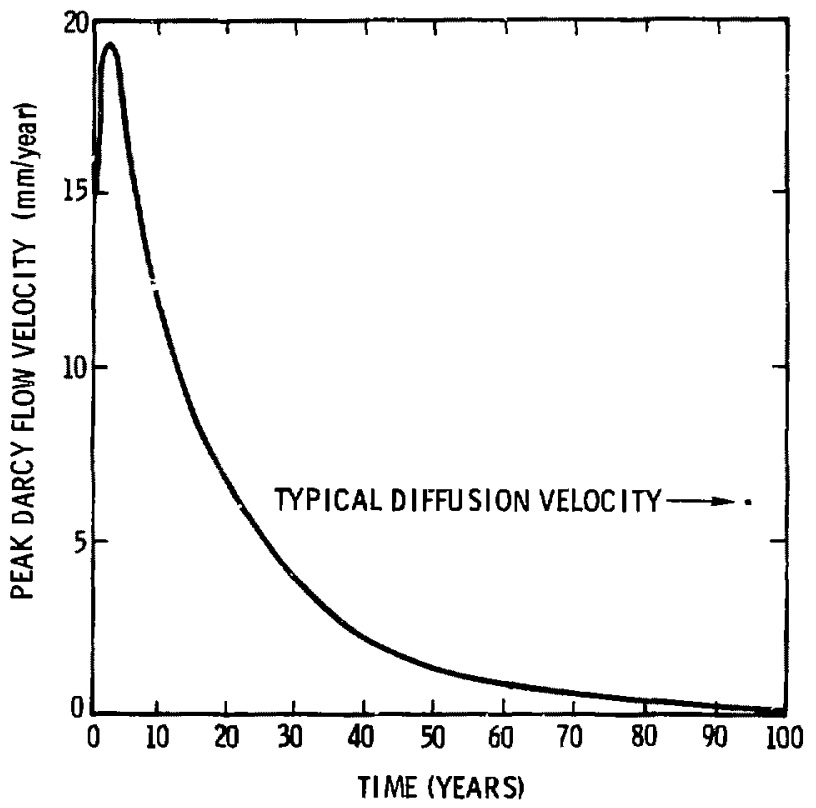

FIGURE 4. FLOW VELOCITY ADJACENT TO A WASTE CANISTER 30 METRES BELOW THE SEDIMENT SURFACE. 
For all elements, except iodine, it is asgumed that the molecular diffusion coefficient is $0.01 \mathrm{~m}^{2} /$ year $\left(3.0 \mathrm{E}-10 \mathrm{~m}^{2} / \mathrm{s}\right)$, longitudinal dispersiricy factor is $6.1 \mathrm{~m}$, the transveree dispersivity factor is $0.61 \mathrm{~m}$, the porosity of the sediment is uniform and equal to 0.75 . For iodine, the molecular diffusion coeficient is $0.018 \mathrm{~m}^{2} /$ year. Values for the equilibrium partition coefficient, $\mathrm{K}_{d^{\prime}}$ were obtained by fitting a limited amount of laboratory data, and were approximated as follows:

$$
\begin{array}{ll}
\text { Plutoniun: } & \mathrm{K}_{\mathrm{d}}=\frac{100}{1+3 \mathrm{ECC}}+0.01 \\
\text { Cesium: } & \mathrm{k}_{\mathrm{d}}=\frac{10}{1+200000 \mathrm{C}}+0.1 \\
\text { Iodine and Technetium: } & \mathrm{k}_{\mathrm{d}}=\frac{0.0001}{1+10000 \mathrm{C}}
\end{array}
$$

where $\mathrm{C}$ is the fluid ionic concentration in $\mathrm{kg} / \mathrm{m}^{3}\left(\mathrm{k}_{\mathrm{d}}\right.$ "alues are in $\mathrm{m}^{3} / \mathrm{kg}$ to obtair $m 1 / 9$ multiply by 1000). Valence states of $\mathrm{Cs}$ and Pu are assumed to be +1 and +4 , respectively.

The fluid properties usei by the code MarIAH to calculate the convective velocities vary with temperature and plots of these guantities are shown in Figure 5. A nominal fluid density of $1000 \mathrm{~kg} / \mathrm{m}^{3}$ was used. Additional sedinent property values used in the MARIAH calculations are:

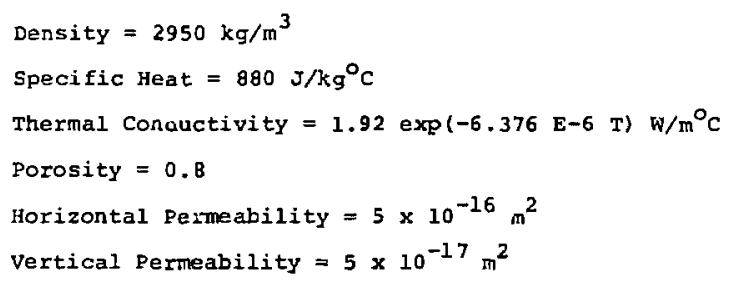

This conservative overestimate of dispersivity factor is used because good data is not currently available, and the low velocities calculated make dispersion very small compared to molecular diffusion so that errors in this factor do not affect the results. 


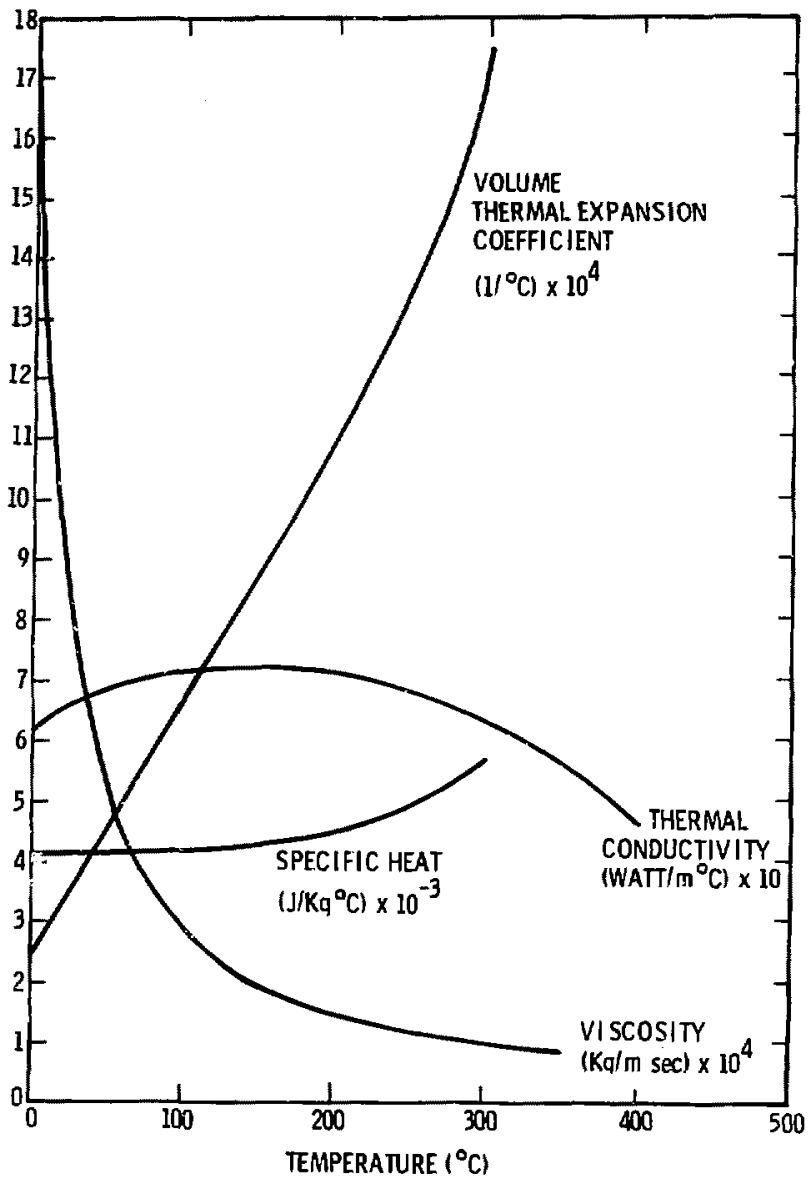

FIGURE 5. VARIATION OF FLUID PROPERTIES WITH TEMPERATURE AT 600 BARS. 
The release in each case is assumed to be of the whole canister inventory at zero time. At the bedrock and the outer periphery of the computational domain, a zero flux condition is assurad so that all nuclides released from the canister (which do not decay) will eventually diffuse to the surface.

Although the results of only four nuclide migration calculations are discussed, in order to obtain those results parent and daughter nuclides were :onsidered simultaneously. Table 1 lists all the nuclider associated with each calcuation and their assumed canister inventory value at zero time.

TABLE 1

INITIAL CANISTEF. INVENTORIES OF ISOTOPES USED IN THE CALCULATIONS

\begin{tabular}{cc} 
Radionuclide & Mass in Canister $(\mathrm{kg})$ \\
\hline $243_{\mathrm{Am}}$ & 0.121 \\
$239_{\mathrm{NP}}$ & $1.0 \mathrm{E}-7$ \\
$243_{\mathrm{Cm}}$ & $5.92 \mathrm{E}-5$ \\
$239_{\mathrm{Pu}}$ & $3.58 \mathrm{E}-2$ \\
$235_{\mathrm{U}}$ & $1.0 \mathrm{E}-5$ \\
\hline $129 \mathrm{I}$ & 0.305 \\
$.129 \mathrm{Xe}$ & $1.178 \mathrm{E}-4$ \\
\hline $99_{\mathrm{TC}}$ & 1.13 \\
$99_{\mathrm{Ru}}$ & $4.32 \mathrm{E}-5$ \\
\hline $137 \mathrm{Cs}$ & 1.33 \\
\hline $137 \mathrm{Ba}$ & $2.01 \mathrm{E}-7$ \\
\hline
\end{tabular}




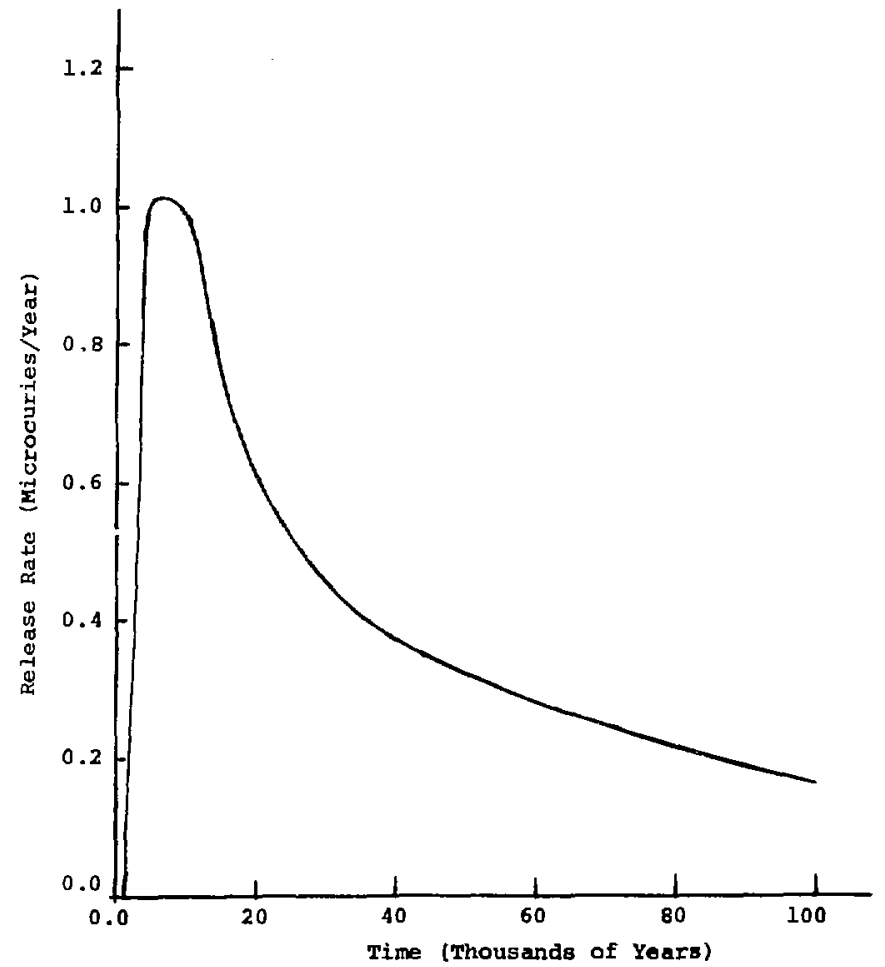

FIGURE 7. Release Rate of ${ }^{129}$ I from the Sediment surface covering a Single Canister at $30 \mathrm{~m}$ Depth. 
Figure 8 shows a similar release rate profile for ${ }^{99}$ TC. The peak value of $180 \mu \mathrm{Ci} /$ year is much higher than that for ${ }^{129}$ I because both the initial canister invontory and the specific activity of ${ }^{99} \mathrm{Te}$, which beta decays to ${ }^{99}$ Ru with a h? - -life of 213,000 years, are higher.

The significance of such release rates in terms of human or ecological hazards can only be detemined by a comprehensive analysis of the water column transport mechanistos and marine bio system concentration mechanisms. Some perspective on the fredicted release rates can be obtained, however, by a comparison with other oceanic radioactive sources. A single storm in the mid-sixties could wash out more than $10^{6} \mu \mathrm{Ci}$ of beta activity from residual atmospheric sources. ${ }^{4}$ Total oceanic atmospheric deposition of ${ }^{90} \mathrm{Sr}$ alone in 1978 exceeded $8 \times 10^{10} \mathrm{HCI}^{5}$ such rates are very much higher than the worst calculated predictions (even for thousands of canisters). In addition to atmospheric deposition, natural radioactive substances are constantly diffusing from the pelagic clay sediment. For the axisymmetric case for which the IONMIG calculations were made, the per canister azea is based on a canister spacing of $1 ? 0 \mathrm{~m}$. This results in an average per canister release of $8.9 \times 10^{-5} \mu \mathrm{Ci} /$ year $-\mathrm{m}^{2}$ for ${ }^{129} \mathrm{I}$ and $1.6 \times 10^{-2} \mu \mathrm{Ci} /$ year $-\mathrm{m}^{2}$ for ${ }^{59} \mathrm{TC}$. These fluxes compare to natural radium and radon fluxes of $3.5-8.8 \times 10^{-4} \mathrm{\mu Ci} /$ year $-\mathrm{m}^{2}$ for ${ }^{226} \mathrm{Ra}$ and $0.26-0.88 \mathrm{\mu Ci} / \mathrm{year}-\mathrm{m}^{2}$ for ${ }^{222} \mathrm{Rn} .{ }^{6,7}$ Based on this comparison, one may hypothesize that the immediate exposure effects of the released ${ }^{129} \mathrm{I}$ and ${ }^{99}$ TC on benthic organims would be negligible in as much as they evolved in a much more intense field. Confirmation of this hypothesis awaits completion of ongoing research and experimentation on biological concentration, wate $i$ =olumn trasport mechanisms, and development of pathways-to-man models. 


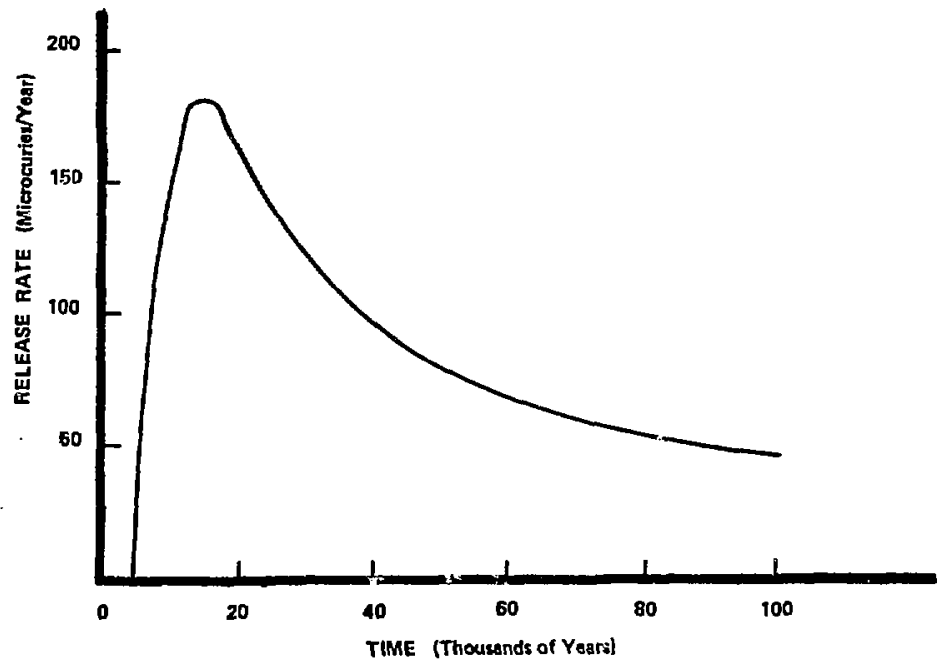

FIGURE 8. Release Rate of ${ }^{99}$ Tc from the sediment surface covering a Single Canister at $30 \mathrm{~m}$ Depth.

21 


\section{CONCLUSIONS}

The development of a computer code to be used as a tool in assessing the transport of waste nuclides through ocean sediment is proceeding satisfactorily. Preliminary calculations of the migration of Cs, Pu, I, and Tc from a point 30 metres below the sediment surface have been made. Elements with short halflives (less than 500 years) such as ${ }^{137} \mathrm{Cs}$ decay to negligible values before reaching the surface. Actinides many of which have large values $k_{d}$ (above $10,000 \mathrm{gm} / \mathrm{ml}$ ) move very slowly and also do not reach the surface until seyond 1,000,000 years, Long-lived figsion products with low adsorption coefficients, such as ${ }^{129} \mathrm{I}$ and ${ }^{99} \mathrm{TC}$, are the most difficult to contain. For those nuclides, it must be shown that the low rclease rate and low specific activity reduce the hazards from them to an acceptable level, or additional engineered barriers must bc Irovided. 
REFERENCES

1. R. W. MacCormack, "The Effect of Viscosity in Hypervelocity Impact Cratering," AIAA. Paper No. 69-354, 1969, or "Numerical Solution of the Interaction of a shock Wave With a Laminar Boundary Layer, "Proc. of the Second Intl. Conf. on Numerical Methods in Fluid Dynamics, September 15-19, 1970, University of California at Berkeley.

2. R. T. Dillon, R. B. Lantz, and S. B. Pahwa, "Risk Methodology for Geologic Disposal of Radioactive Waste: The Sandia Waste Isolation Flow and Transport (SWIFT) Model," SAND78-1267, NUREG/CR-0424, October 1978.

3. M. J. Bell, "ORIGEN--The ORNL Isotope Generation and Depletion Code," ORNL-462B, MaY 1973 .

4. S. J. Hail, "Radioactivity in Precipitation: Case Studies from the 1964 Spring Season," Radioactive Fallout from Nuclear Weapons Tests, CONF-765, pp. 532, November 1965 .

5. H. W. Feely and I. E. Toonkell, "Worldwide Deposition of $90 \mathrm{Sr}$ Through 1978," EML-363, Eng. Measurement Laboratory Quarterly Report, October 1979.

6. J. K. Cochran, "Geochemistry of ${ }^{226}$ Ra and ${ }^{228} \mathrm{ka}$ in Marine Deposits, PhD Dissertation, Yale University, New Haven, Connecticutt, 1979.

7. G. R. Heath, Department of Oceanography, Oregon State University, private communication. 